\title{
Discussion on the Teaching of Art Color Design in Higher Education in the New Era
}

\author{
Lufang Guo \\ Anyang Preschool Education College, Anyang, Henan, China
}

Abstract:

The success and failure of color matching are directly related to work efficiency, sleep, personality and so on. Color matching course can not only cultivate students' creative thinking, but also improve their aesthetic ability and expression ability. This paper studies the teaching methods of art color design in Higher Education in the new era. Color matching course is an important part of the teaching and training of art design major, and it is also an essential basic skill for every environmental art student. Through the research on the meaning, types and characteristics of color, as well as the concept and category of color matching, combined with the experience and lessons in the teaching process, this paper demonstrates various teaching methods of indoor color design in practical teaching. The experimental research shows that the method proposed in this paper can improve the teaching efficiency of art color design.

Keywords: Color Matching, Creative Thinking, Color Design, Teaching Methods.

\section{INTRODUCTION}

In our daily life, we often hear people discussing what color symbolizes or what kind of feeling it symbolizes. Color is symbolic [1]. Some colors can symbolize sadness and sadness, while others can symbolize change and auspiciousness. Some people have misunderstandings in understanding that the symbolic meaning of color is the attribute of color, but it is not so. In general, the human and natural attributes of color constitute the attributes of color [2-3]. People have made a basic definition of color according to their own rational understanding and objective perception of color. This definition belongs to the natural attribute of color [4-5]. People define the attribute of color by influencing their religion, culture, region, nationality, politics, science and technology, political power and production, which is the humanistic attribute of color. There are also contradictions between the natural and humanistic attributes of color [6].

In the nature where we live, because of color, the world becomes colorful. In nature, any substance has its own color, which shows that color and nature exist at the same time. In the 
Article History: Received: 28 October 2021 Revised: 05 December 2021 Accepted: 10 January 2022 Publication: 28 February 2022

whole nature, the existence of color has very special significance. Because of the makeup of color, nature becomes full of vitality, expressiveness and symbolism. Color is the key factor to reflect the beauty in people's life [7-8]. Each of us has lived in a world full of all kinds of colors since we were born. The existence of color also plays a vital role in human development. Because the existence of color makes people's life colorful, when different colors enter people's vision and stay in people's brain, people have different color senses in their thoughts, which act on people's emotions [9]. It promotes the development of people's thinking and the change of emotion.

In modern times, people's pursuit of color is becoming stronger and stronger. People use color more and more in life, and people continue to enjoy the happiness brought by color. Color fills people's life and can bring people different psychological feelings. Now color is also greatly applied in interior decoration. People's requirements for interior design not only stay at the level of comfort and environmental protection, but also pay more and more attention to color matching, because good interior color matching can optimize interior decoration, And can set off a comfortable atmosphere, which has an important impact on people's emotion. Therefore, in the process of interior design, we must put the collocation of colors in the first place. Only a refreshing color space can make the host happy [10]. There is no distinction between beauty and ugliness in a single color itself, but if there is no good matching of colors in interior design, it will reduce the soul of colors, so a good matching can make colors more active and vivid.

Most of the time, our sensory system will not deliberately detect the vast majority of colors, and often make unconscious choices when choosing colors. When choosing colors, you can't choose them only by reasoning and analyzing information, but the necessary professional knowledge and skills must be the basis for understanding indoor colors. Starting with the relationship between color matching and interior design, this paper expounds the importance of color matching and the transformation of thinking mode for interior space design, and discusses and studies the teaching and training methods of color matching through examples.

\section{TRAINING OF COLOR MATCHING IN INTERIOR DESIGN TEACHING}

In the interior space design, the thinking method is very key. In all designs, only the thinking mode of interior design is independent, so it has its own particularity. Only by changing and improving the thinking mode can we ensure the novelty and uniqueness of space design. In the interior design, different students have different ways of thinking. There are two common ways of thinking, one is the image way of thinking, the other is the abstract way of thinking. Especially in the interior space design, these two ways of thinking are very representative and typical.

In some designs, students do not change their way of thinking. They only use abstract 
Article History: Received: 28 October 2021 Revised: 05 December 2021 Accepted: 10 January 2022 Publication: 28 February 2022

thinking or image thinking in a design. Some of them believe that image thinking is too perceptual and should be used by art creators, while others believe that abstract thinking is too rational and can be systematically expressed only by philosophical thinking. Therefore, in the works designed by these students, they often show a relatively single phenomenon. They only use one way of thinking to express it in multiple works. This one-sided state has seriously affected the creators' way of thinking and caused great obstacles in the process of creation and design. Therefore, only by constantly changing their own way of thinking and integrating a variety of ways of thinking can students make their works unrestricted and express their multilevel way of thinking in specific works. Only when the way of thinking is alive, the soul color of interior design can be alive, and the space can be flexible in interior design. Because from the perspective of visual law, color is easier to attract people's attention and have a strong impact on people's emotions than shape. Therefore, in color matching, in order to increase the attraction of color, we must constantly change the way of thinking. Use rich imagination for color matching. Only with color imagination can we give full play to creativity in color matching, which also requires the transformation of thinking mode. Through flexible transformation, we can make the color configuration more coordinated and make the color contain creative ability. Through rich imagination, we can give color deeper symbolic meaning and special emotion, so as to make the creator's thinking more divergent, so as to stimulate association to obtain inspiration, make the color structure more dynamic and innovative, and make the color combination more vivid and emotional.

Only when the way of thinking has the characteristics of visualization and diversification can it be called "image thinking". When students use image thinking, their works are very diversified, and the contents of the works get rid of the constraints of a single direction. When students think with image thinking, they can look at things from many different perspectives, Then integrate these diversified materials into Wanfang Data into the design, so that we can express beautiful things in more forms. When students have their own personal feelings and feelings about an object, they will look at such an object with image thinking. In the design process, students will continue to imagine and associate such an object, fully integrate with their own aesthetic judgment, personal feelings and supervisor's understanding, and finally express such an object in the form of creation. When designing with image thinking, we should take the shape of things as the basis of design, and add our own aesthetic judgment on the basis of shape. When designing space, students can't do without image thinking. In addition to reflecting students' observation and feeling of real life, students also need to make full fantasy, imagination and association, Make breakthroughs and innovations in reality, so that better space design schemes can emerge.

Abstract thinking has another nickname, that is, abstract logical thinking. Some viewpoints found by students in intuition should form a more rational way of thinking through specific sorting, analysis and synthesis. This way of thinking should retain some laws, attributes and 
Article History: Received: 28 October 2021 Revised: 05 December 2021 Accepted: 10 January 2022 Publication: 28 February 2022

principles in the original viewpoint. Only through continuous practice can students understand the laws and essential attributes of things that need to be designed, and students can well grasp the key and essential characteristics of things, and then carry out specific design through the integration of thinking logic. When designing interior space, students should use more scientific methods to elaborate the essential attributes of things, use abstract logical thinking to recognize things, and finally express the students' cognitive results. In the actual design, a good design scheme must change the thinking concept and comprehensively integrate a variety of thinking modes, so that in the design, the works will not be too rigid or single design. After the transformation and integration of thinking, it is believed that better interior design works can be obtained.

In the interior design of the room, we should maintain color harmony, and put the reasonable collocation of colors first. No matter what color scheme students want to adopt in the design, we must ensure the harmony of color collocation. However, the monotonous and dull color matching can not be mistaken for a harmonious matching. In the matching process, there needs to be a certain contrast, mainly to master the indoor contrast. We should emphasize the color and highlight the role of color in the atmosphere, which is the most noteworthy point in interior design. When training indoor color matching, we should choose the color from the given chromatogram. When selecting the color, we should consider people's psychological factors and the overall indoor color matching. This method is suitable for students with weak sense of color.

When training students in color matching, find some matched chromatograms from the color matching data, select a group of color matching consistent with the design style from the chromatograms according to the design requirements, and apply this group of colors to each carrier of the scheme. For example, when designing a modern room, if students want to express a gorgeous feeling, they can find a group of gorgeous color combinations in the chromatogram (as shown in Figure 1), determine the main color of the room as milky white, use milky white for the ceiling and wall in the room, and slightly deepen the colors of the ground, doors and windows, You can choose slightly darker colors such as orange gray for decoration. When matching furniture colors, you can choose some relatively bright colors, such as dark red and orange, which can form an embellishment effect on the overall effect (as shown in Figure 2).

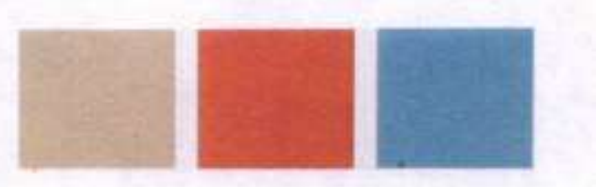

Fig. 1: A group of gorgeous color combinations in the chromatogram 
Article History: Received: 28 October 2021 Revised: 05 December 2021 Accepted: 10 January 2022 Publication: 28 February 2022

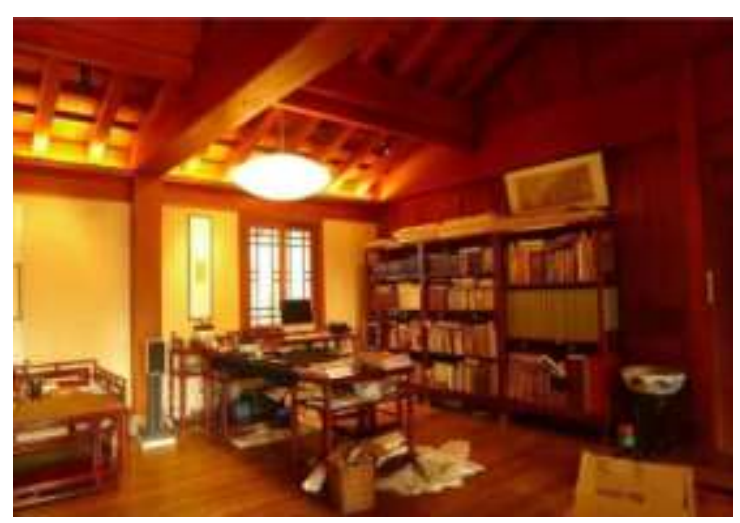

Fig. 2: Gorgeous interior design

If you want the designed room to be warm and highlight the lively elements, you can choose warm color as the basic tone of the room (as shown in Figure 3). Generally, warm colors such as orange and red are used as the color of the wall. In addition, some room layout, such as tablecloth and carpet, should use warmer colors; When some small ornaments are arranged, more colors can be used to make these ornaments show their colors. Indoor curtains and other fabrics can adopt the color of big flowers. You can also decorate the room with various lights and many green plants, which can make the whole room have a sweet and warm feeling (as shown in Figure 4).

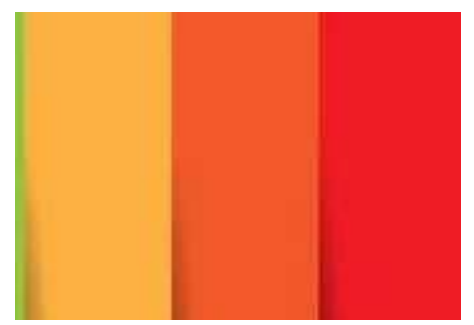

Fig. 3: Warm tones 
Article History: Received: 28 October 2021 Revised: 05 December 2021 Accepted: 10 January 2022 Publication: 28 February 2022

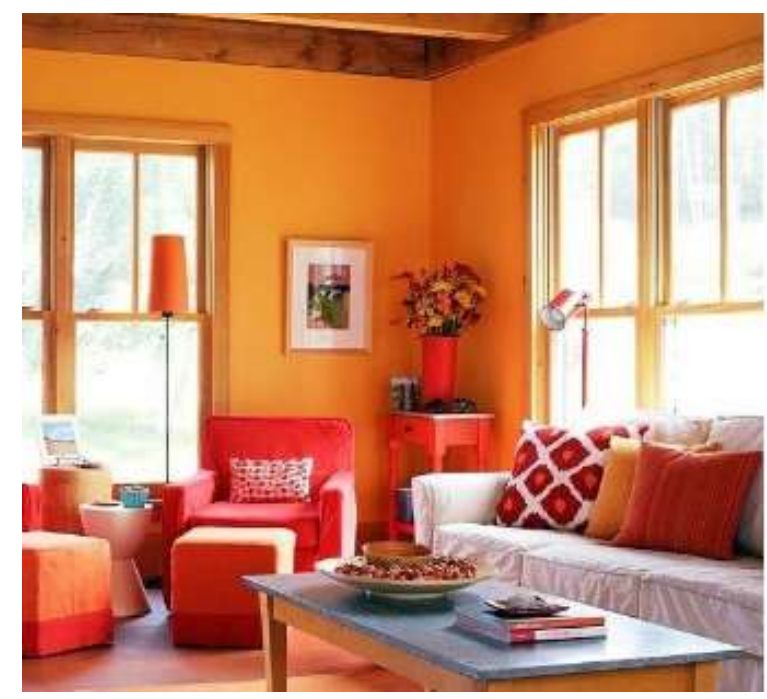

Fig. 4: Warm tone interior design

\section{DESIGN OF COLOR TEACHING COURSE}

We have mastered the selection method of color. To successfully apply it in the scheme design, we need to have a series of practical case training. For example, given a scheme for office space, let students make a scheme, and then determine the color code that meets the needs of the office environment. When designing, select the color according to the color code, so as to avoid the blindness of students' color selection. In the development training, we can do targeted color cognition training for students from the perspective of professional color, train students in the application of color from the needs of interior design posts, train students in the creativity of subjective color and the style of color expression, and carry out development training for students' color from four aspects.

In the process of expansion training, to improve students' cognition of color, students should be given some professional color cognition training. This training can enable students to carry out color sketching of still life through practical training. In this way, students can personally experience the use of object color and summarize the color and morphological characteristics of objects in the process of practice, In addition, they have a comprehensive design for their whole picture color layout, and can add their own color reorganization and innovation. After such training, students' subjective ability of color will be strengthened, and their basic cognition of color has been changed in students' thoughts through their own innovative Association, Their subjective color consciousness and the application of color comprehensive expression have been strengthened.

In general, the concept of interior color design shows personal living habits, personality, temperament and style hobbies. Only by allowing students to personally make interior $3 \mathrm{~d}$ 
Article History: Received: 28 October 2021 Revised: 05 December 2021 Accepted: 10 January 2022 Publication: 28 February 2022

design renderings, can students express their way of thinking and ideas into the interior decoration style. In this way, after fully mastering the theory, they can pass the practical training course, Through hands-on practice, the theoretical viewpoints mastered are quoted into their own practical works, so that when doing color matching, students subjectively train their sense of innovation. At the same time, they should consider that their works must meet the coordination of color, so as to further train students' thinking and practical ability in future work. It is convenient to modify the color pattern by using the computer effect drawing. In class, students can make a set of models and express them with different color schemes (Fig. 5 and Fig. 6), so that students can experience different feelings brought by different styles in the process of modification, which is conducive to cultivating students' color matching application ability.

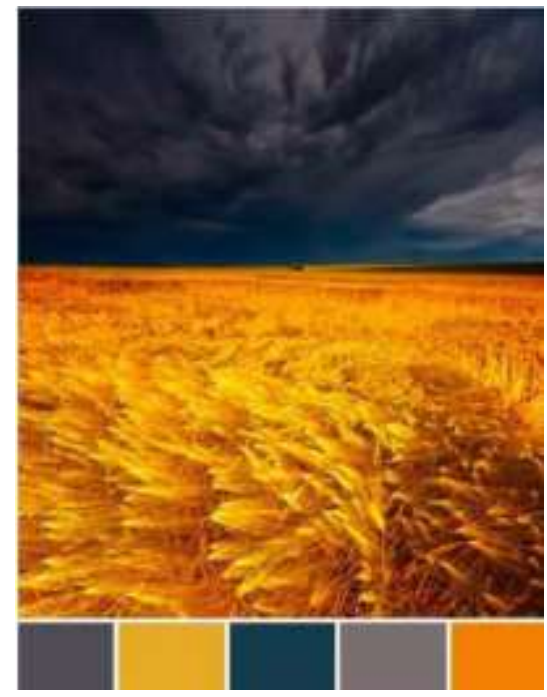

Fig. 5: Color application training example 1 
Article History: Received: 28 October 2021 Revised: 05 December 2021 Accepted: 10 January 2022 Publication: 28 February 2022

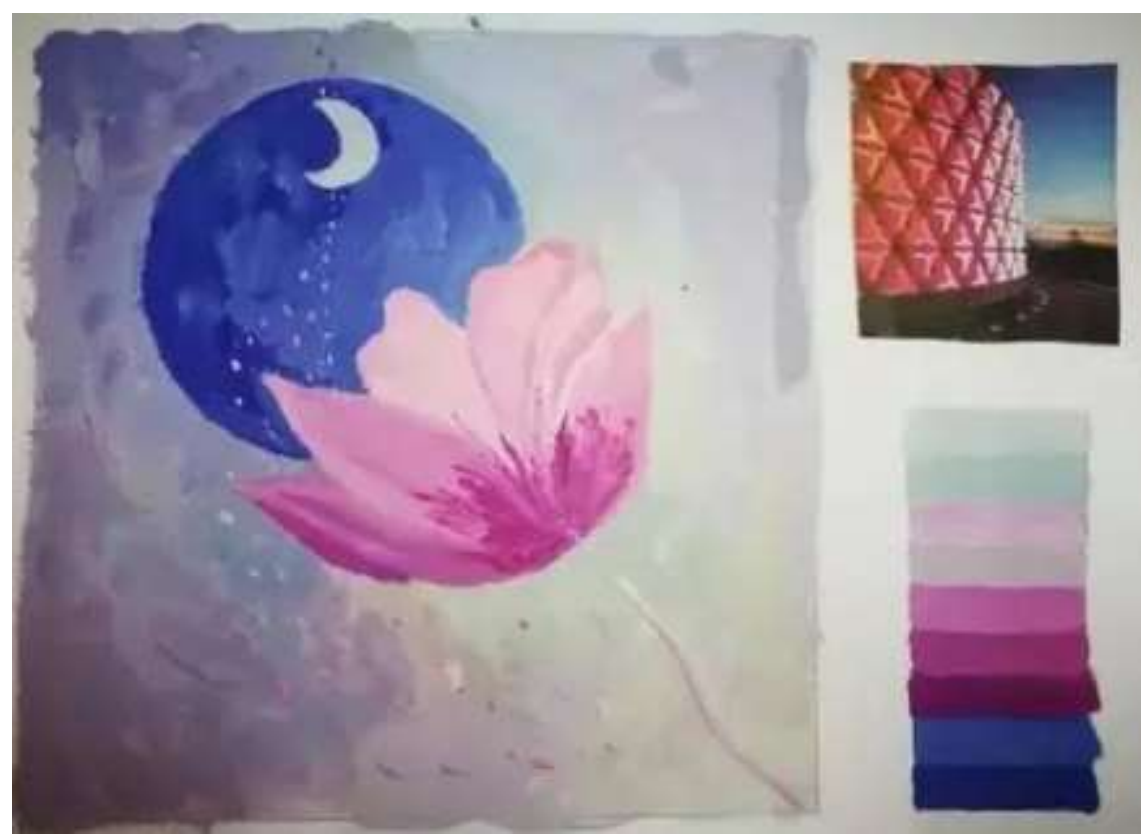

Fig. 6: Color application training example 2

After the expansion training, the knowledge mastered by students is more comprehensive. In daily teaching, students only design the space according to the hypothetical examples in the classroom, as well as the color matching and creativity in the space. They do not really design for a residence, and only one-sided color matching for a part of the space in daily learning. In the process of practical training, students should be given the opportunity to carry out creative design planning for an indoor residential or commercial space from beginning to end, and carry out color matching and color selection completely according to their own subjective ideas. In this way, students' color ability can be trained in an all-round way, and when facing the whole space, Still have the ability to comprehensively analyze color.

Subjective color awareness and color comprehensive expression training can enable students to apply different styles in their mind and the color concepts that should be used in different styles to practice, and enable students to apply their own design concepts to specific interior. In this way, they can assume the customer needs, selected style and personality of the design, and enable students to carry out comprehensive design and conception. In this way, students' practical ability and expansion ability will be comprehensively cultivated, and their social practice ability and comprehensive level will be improved.

\section{CONCLUSION}

In the teaching process of interior design, both teachers and students should realize that the soul of interior environmental design is interior color matching. Interior color will affect 
Article History: Received: 28 October 2021 Revised: 05 December 2021 Accepted: 10 January 2022 Publication: 28

February 2022

the environmental atmosphere, comfort and sense of space of space. The harmony of color also directly affects people's psychological and physiological situation. Only by mastering the collocation and application of colors in the classroom can we meet the indoor functions and organically combine the quality, color, light and shape of various indoor objects in the process of interior design. At this time, a whole can have reasonable and harmonious characteristics. Each color, as a member of the whole, can meet the requirements of the whole. Its reasonable degree can meet the requirements of artistic effect, and has its unique advantages. It can give full play to this whole, so as to jointly create an indoor environment with high practicability and high comfort.

\section{REFERENCES}

[1] Liu Baocheng, Wang Yu. on the Application of Graphic Language in Graphic Design. Packaging Engineering, 2006, 27 (004): 255-257

[2] Peng Juan. Graphic Language and Text Language in Packaging Design. Packaging Engineering, 2008, 29 (006): 116-118

[3] Lin Qi. Semiotic Analysis of Graphic Language. Lanzhou Academic Journal, 2006, 000 (005): 206-207

[4] Zhang Jianyu, Yi Xiduo. Graphical Language Model and Representation Based on Event. Packaging Engineering, 2020, V.41; No.420 (06): 200-205

[5] Zhang Guogang, Wang Jianhua, Wu Anbo. Design and Optimization of Xvgml Language and Its Integration with Knowledge System. Chinese Journal of Image Graphics, 2003 (02): 118-122

[6] Wang Liting. An XML Based Interactive Graphic Description Language for Mobile Platform. Computer Science

[7] Xie Xuansong, Sui Yangyi, Lin Jun. Graphical Language Structure and Operation Model. Journal of Jilin University (engineering Edition) (02): 219-223

[8] Yan Guilan, Liu Jiayao. Design of Algorithm and Driver for C Language Graphic Printing. Journal of Huaqiao University (natural Science Edition), 1993 (03): 382-386

[9] Liang Li, Chen Rui. the Realization of Figure / Background Theory in Tang Poetry and Its Effect on Artistic Conception. Foreign Languages, 2008, 031 (004): 31-37

[10] Meng Cun. Research on Graphic Language Expression of Visual Communication Design. Packaging Engineering, 2013, 034 (022): 20-23 